\title{
Atos de comércio e contratos administrativos
}

\author{
Ruy Cirne Lima \\ Professor catedrático de Direito Admi- \\ nistrativo e Ciência da Administração \\ na Faculdade de Direito da Universi- \\ dade do Rio Grande do Sul.
}

1. Não obstante a diversidade das matérias, o Direito Administrativo e o Direito Mercantil denotam afinidades evidentes, quanto ao processo de formação, do qual histórica e lògicamente, receberam, ambos, a sua estrutura atual.

Surge o Direito dos Mercadores em torno das jurisdições consulares (1), como o Direito da Administração em torno das jurisdições administrativas; e destinam-se, ambos, a regular formas determinadas de atividade: aquele, a mercancia, êste, a administração pública.

Não admira, pois, que em ambos coincidam característicos fundamentais: a elasticidade, com que um e outro abrangem e empolgam os fatos; e a supletividade, com que se ajustam, ambos, às construções jurídicas, normativamente mais estáveis, e socialmente mais amplas, de outras disciplinas.

São ambos, na verdade, o Direito Mercantil e o Direito Administrativo, manifestações distintas de processos formativos semelhantes. Podemos, se desejarmos, reuní-los sob denominação comum, chamando-lhes, a ambos, "jus honorarium". Do "jus honorarium", a que já a propulsão ju-

(1) Waldemar Ferreira Tratado de Direito Mercantil Brasileiro, t. I. São Paulo, 1934, n.o 29, p. 125 e 134. 
risdicional os assemelha, tiram êles os característicos da elasticidade e da supletividade, que tão intimamente os aproximam.

Cornélio Nepos pôde dizer de Catão, e assim demonstrar a admirável elasticidade do "jus honorarium": "...multas res novas addidit in edictum" (2). Da supletividade dêste, à sua vez, Papiniano: “jus praetorium... praetores introduxerunt... supplendi juris civilis gratia, propter utilitatem publicam" (3).

Tais característicos são, ainda hoje, necessitados rigorosamente pelo conteudo mesmo de nossas duas disciplinas, como outrora o foram pela natureza própria do direito honorário. O Direito Mercantil e o Direito Administrativo regulam formas especificas de atividade: hão-de ser, portanto, supletivos aos demais ramos do direito que regulam, especificamente, outras formas de atividade ou, genèricamente, tôda a atividade jurídica não especialmente regulada. A seu turno, regular forma determinada de atividade não é a mesma cousa que regular as atividades de pessoa determinada. A firmeza de regulação que conviria à identidade duradoura da pessoa, desconviria ao curso vário e mutável de uma forma específica de atividade; reclama, esta, mobilidade e expansão ou, seja, elasticidade.

2. Das analogias entre o Direito Administrativo e o Direito Mercantil, a mais fecunda em consequências é, fora de dúvida, essa que resulta da compreensão das duas disciplinas, ambas restritas à regulação jurídica de formas peculiares de atividade. Trata-se aqui, realmente, de uma analogia de conteudo, posto que formal, e não meramente de uma semelhança de origem; de uma conexão lógica, e não simplesmente histórica.

(2) CAто, 2.

(3) Dig., lib. I, ti.t. I, de justitia et de jure, fr. 7, § 1. 
Com fundamento nessa analogia, é que pode e deve construir-se, por exemplo, no Direito Administrativo, a doutrina dos contratos administrativos, "ad instar" da doutrina dos atos de comércio, no Direito Mercantil.

3. Sorrirão, talvez, das proporções do intento os "doctores privati juris", a quem o capítulo dos contratos de Direito Público Interno sói aparecer, antes como um campo de batalha, do que como base de construções jurídicas perduráveis.

A rigor, porém, o direito todo é um campo de batalha. o nosso velho Gama advertia em seu tempo: "nihil tam iniquum quod careat alicujus doctoris opinione" (4) . Escapa, por ventura, ao fragor das controvérsias ou à anomalia das singularidades, a doutrina do contrato no Direito Privado?

Não desconhecia o Direito Privado Romano relações bilaterais, oriundas do contrato (5)? Não se recusou, na França, à doação a natureza de contrato (6)? E já no século XIX, Scihlossmann não negou que, do contrato, pudesse nascer a obrigação (7)?

(4) Decisiones, Antuerpiae, 1735, lib. II, cent. III, dec. 202, n. 3 , p. 255: "ut etiam dicit RoDericus SOAREZ, in allegatione 24" E antes de todos, Cícero (De Divinatione, 2,58): "nihil tam absurde dici polest quod non dicatur ab aliquo Philosophorum"

(5) Dernburg, Die Compensation nach römischem Rechte, Heidelberg, 1854 \& 8, p. 78: “ die Grundsätze des römischen Obligationsrechts immer unverständlich bleiben (müssen), so lange wir jene Ansicht von der Einheit der mebreren Obligationen aus einem Geschaft nicht aufgeben"; JHering, L'Esprit du Droit Romain, trad. de O. de Meulenaere, t. IV, Paris, 1888, § 64, p. 195.

(6) Gronge, Teoria delle Obbligazioni, t. III, Firenze, 1891, n. ${ }^{10}$, p. 12

(7) Der Vertrag, Leipzig, 1876, p. 273: "Eine Obligation entsteht niemals, somdern nur das Urtheil in uns, dass Jemand schuldig sei, und est ist unzweifelhaft das ein solches Urtheil sich in uns nicht bilden kann, wenn das Versprochene geleistet ist."

p. 104 e 105 . 
Se quisermos restringir-nos ao Direito Mercantil, do mesmo passo que BALDo postulava a equiparação, "inter mercatores", do "nudum pactum" aos "pacta legitima" $\mathrm{e}$ aos contratos, para o efeito de gerar ação, TARTAGN não limitava o surgimento da ação, em tais casos, aos juizos de equidade, estabelecidos por estatuto ou estilo (8) ? E Duareno não afirmava que, ainda entre mercadores, o "nudum pactum", em caso nenhum, poderia produzir ação (9)? Não se vem discutindo, de resto, até o século XX, se a letra d'e câmbio é, ou não, um contrato (10)?

4. Cumpre, entretanto, reconheçamos que, no Direito Público e, em especial, no Direito Administrativo, as dificuldades do tema são, senão mais ásperas, seguramente, ao menos, mais dilatadias. Aqui, começa-se por perguntar: existe realmente, a figura do contrato no Direito Administrativo?

5. Conforme é sabido, faltava ao Direito Romano um conceito universal de contrato. A convenção das partes não constituia contrato obrigatório, enquanto não assumisse os caracteres de um dos tipos contratuais estabelecidos, ou da estipulação (11).

Não é definição de contrato o texto famoso: "pactio est duorum vel plurium in idem placitum et consensus" (12). Esse texto d'efine, apenas, o acôrdo, um dos elementos do

(8) Carrara, La Formazione dei Contratti, Milano, 1915,

(9) Savigny, Le Droit des Obligations trad. de C. Gérardin e P. Jozon, Paris, 1873, t. II, § 76, p. 396.

(10) Pontes de Mrranda, Letra de Câmbio, Rio de Janeiro, s. d., n.o 3 , d. 7 e 8 .

(11) Ortolaln, Généralisation du Droit Romain, n.o 201 e 202, Explication Historique des Instituts, Paris, t. I, p. 463; Girard, Manuel Elémentaire de Droit Romain, Paris, 1901, p. 428, etc.

(12). Dig., lib II, tit. XIV, de pactis, fr. 1, § 2. 
contrato, - ao demais, segundo BonfaNTE, elemento tão pouco preeminente que o relêvo, a êle dado mais tarde, pode ser havido como uma novidade da jurisprudência (13).

Aceita a concepção romana, a existência da figura do contrato no Direito Administrativo é questão a ser resolvida em função do direito positivo, pela pesquisa casuística daquelas situações, em que ao contrato, ponto de cruzamento ideal de duas ou mais vontades, a lei atribui eficácia jurídica. Tal, a opinião de Guido ZanobinI (14). Olvida, porém, o jurista italiano que, dessa forma, impõe ao Direito Administrativo um retrocesso no tempo, em contraposição a todos os demais ramos do direito.

$\mathrm{Na}$ verdade, a concepção romana do contrato desapaveceu completamente do direito moderno. Saiu-lhe ao embargo, de um lado, o Direito Canônico, o qual, restabelecendo a eficácia do Direito Natural, enunciou solenemente o princlípio de que todo acôrdo de vontades cria obrigações: "Jus Canonicum restituit jus naturae, et ex omni pacto actionem dedit" (15). Resistiu-lhe, de outro lado, o Direito Germânico, com a figura do "wadium" ou, em português, gádea (16), ao influxo do qual a "traditio cartae" veio a substituir a "stipulatio" romana (17). Certo, por precaução, incluia-se, ainda, em todos os atos, a cláusula romana da estipulação. Mas a "opinio juris", que presi-

(113) Sulla genesi e l'evoluzione del "contractus", Scritti Giuridici Varii t. III, Torino, 1926, nota I, p. 108.

(14) Corso di Diritto Amministrativo, t. I, Milano, 1936, p. 267; cf. 5.a ed., t. I, Milano, 1947, p. 179.

(15) Ferraris, Bibliotheca Canonica, Juridica, Moral Theologica t. $\amalg$, Romae 1886, verb. "Contractus in Genere, n." 74, p. 699 .

(16) Pontes de Mrratnda, Dos Titulos ao Portador, n. 12. Manual do Código Civil Brasileiro, de Pavio De LACERda, v. 16, t, I Rio Janeiro 1932 p. 77.

(17) Brunner - v. Shwerin, Historia del Derecho Germánico, trad. de J. L. Alvarez Lopez, Barcelona, 1936, \$ p. 46 e 47. 
dia a todos os atos, não mais correspondía à convicção romana (18).

A essência do contrato é, já agora, o acôrdo das vontades; o Direito Natural retoma o lugar, que o velho direito positivo lhe arrebatara. Pothier escreve, a propósito: "Os princlipios de Direito Romano sôbre as diferentes espécies de pactos, e a distinção que faziam entre contratos e pactos simples, não sendo fundados no Direito Natural, mas desviados da sua simplicidade, não são admitidos em o nosso direito" (19).

Analisando o conteudo dessa noção genérica de contrato e as relações jurídicas a que pode ela estender-se, o grande Savigny opina, a seu turno, que "essas relações podem concernir ao Direito Internacional, ao Direito Público e ao Direito Privado, aplicando-se, a todos êsses casos, a idéia de contrato" (20).

Alçado, desta sorte, o contrato à esfera dos conceitos jurídicos superiores, tão próxima quanto sensível à influência da explicação e da estruturação filosófica do direito, nenhum dos grandes vultos da filosofia jurídica, dentre os mais dignos de menção, intenta relegá-lo ì antiga inferioridade particularista. Neo-tomistas, como CATHREIN (21), néo-kantista, como Stammler (22), realistas, como GÉNY (23), positivistas, como Duguit (24), todos proclamam a

(18) Brugr, Istituzioni di Diritto Civile, Italiano, Milano, 1907, p. 425 e seguintes.

(19) Tratado das Obrigações Pessoais e Recíprocas, trad. de Correa Telles, Rio de Janeiro, 1906, t. I, n.o 3, p. 4.

(20) Ob. cit., t. II, § 52, p. 147.

(21) El derecho Natural y el Positivo, trad. de A. Jardón e C. Barja, Madrid, 1926, p. 198.

(22) Theorie der Rechtswissenschaft, Halle, 1911, p. 275 e 282.

(23) Science et Téchnique en Droit Privé Positif, t. IV, Paris, 1930, p. 210.

(24) Traité de Droit Constitutionnel, t. I, Paris, 1927, § 65, p. 697 . 
transcendência do conceito de contrato, conceito comum ao Direito Internacional, ao Direito Privado e ao Direito Público.

Dever-se-á retornar, sôbre os passos dessa longa evolução, à concepção romana do contrato? Evidentemente não.

6. Aceita, todavia, a noção de contrato como noção genérica, extensivel ao Direito Administrativo, surge a questão de saber se nela se hão-de abranger tão só os contratos das pessoas administrativas entre si, ou também os celebrados, segundo o Direito Administrativo, entre a pessoa administrativa e o particular

Aqui novamente se abre a controvérsia. Uma larga corrente de doutrina recusa-se a admitir a possibilidade de contrato, regido pelo Direito Administrativo, entre uma pessoa administrativa e um particular. Sob diversas formas, os seus representantes invocam, em abono dessa opinião, o mesmo e só princípio do equilíbrio contratual.

Traduz-se o princípio do equilíbrio contratual, já na igualdade perante a lei dos co-contratantes, já na equivalência, para a ordem jurídica, das respectivas vontades na formação do consenso. Ora, diz-se, o particular não é, perante o Direito Público, igual ao Estado. Entre o Estado, soberano, e o particular, súbdito, falar-se em igualdade é cousa inconcebível. Logo, não é possível, em Direito Público, admitir-se a idéia de um contrato entre o Estado, ou outra pessoa administrativa, e um particular. Tal, a argumentação, entre outros, de BornhaK (25). A essa objecão, respondeu, de modo magistral, Georg Jellinek. Negou o ilustre professor de Direito Público que a subordinação do indivíduo ao Estado fosse ao ponto de excluir a posição do indivíduo, como pessoa, diante do Estado. E sinalando

(25) 'Grundriss des Verwaltunsrechts, Lexpzig, 1928, p. 35. 
que tôda e qualquer pretensão do Estado, face ao indivíduo, deve assentar em um fundamento jurídico, concluiu que a limitação do poder do Estado pelo direito e o reconhecimento, pela ordem juridica, da personalidiade do indivíduo, criam, a êste, um "status libertatis", não só de fato, como decorrência de sua natureza humana, mas própriamente juridico. Dentro nessa esfera de liberdade, o particular é, pois, jurìdicamente igual ao Estado (26).

Variante da argumentação, a que JeLlinek dieu resposta admirável, é a doutrina nacional-socialista, adversa ao contrato do Direito Público entre o Estado e o particular, exposta pelo professor Oto Koellreuter. Na outrora chamada Nova Alemanha, a capacidade jurídica da pessoa, diante do Estado, ficara reduzida a um mero "status subjectionis". A inserção do indivíduo na comunhão do povo dissolvia-lhe a personalidade na massa. A igualdade e a proporcionalidade, que devem guiar a ação do Estado em face da massa, excluiam, por consequência, a idéia de contrato entre o Estado e o particular, de vez que êste, pela singularização do contrato, viria, assim, a sobrepor, diante do Estado, a sua pessoa à massa (27).

7. Suposta a igualdade, perante o Direito Público, entre o particular e o Estado, não se esgota, porẻm, o problema. Há equivalência, perante o Direito Público, pergunta-se, já agora, - entre a vontade do particular e a vontade do Estado, para a formação do ato jurídico?

Oreste Ranelletti, doutor insigne do Direito Administrativo, assim se exprimiu a respeito: “se o negócio é de Direito Público, o particular, agindo como tal, não pode concorrer com a sua vontade para a formação do mesmo.

(26) System der subjektiven öffentlichen Rechte, Freiburg I. B., 1892 , p. 78 e seguintes; cf. a $2 .^{a}$ ed., Tübingen, 1905 p. 866 e seguintes.

(27) Deutsches Verwaltungsrecht, Berlin, 1936, p. 76. 
Só um sujeito de Direito Público... pode formar um ato de Direito Público" (28). Salva, no entanto, a autoridade do jurista, o argumento não convence. Não existem vontades de Direito Privado e vontades de Direito Público. Tanto faz que a vontade seja manifestada pelo particular, como pelo Estado. Os seus efeitos dependem da norma jurídica, e não do sujeito. E' certo que, para a conceituação do ato administrativo, a ordem jurídica reclama qualificação subjetiva: a pessoa administrativa como agente (29). Mas é visto que isso não exclui a possibilidade da participação do particular na formação do ato. Essencial à manutenção do conceito de ato administrativo é, apenas, que ao particular não seja dado praticá-lo por si só.

'A alegada falta de equivalência entre a vontade do Estado e a vontade do particular sugere, ainda, outra ordem de argumentação. Tal é a que acena à ausência de discussão livre, entre o Estado e o particular, acêrca das cláusulas e condições dos contratos de Direito Público. Em regra, realmente, o Estado fixa, com antecedência, em leis, regulamentos, ou "cahiers de charges", as estipulações do contrato. Ao particular incumbe aceitar ou rejeitar o con. trato assim estruturado, mas aceitá-lo ou rejeitá-lo por inteiro. Não havendo livre discussão, poderá haver contrato (30)?

A essa objeção, responde o professor Mário MASAGÃo: “ $E$ ' frequentíssimo, no domínio contratual mesmo de Direito Privado, estatuir uma das partes as normas, e a outra

(28) Le Guarentigie della Giustizia nella Pubblica Amministrazione, Milano, 1937, p. 149.

(29) Nossos Princípios de Direito Administrativo Brasileiro, Pôrto Alegre $193 \overline{9}, \S 9$, p. 73; nosso Direito Administrativo e Direito Privado, Pôrto Alegre, 1950, p. 15.

(30) Morin, La Révolte du Droit contre le Code, Paris, 1945, p. 23. 
as aceitar, apenas. Nem por isso deixa de haver contrato. o passageiro não discute, na estação ferroviária, ao adquirir um bilhete, nem o preço, nem o horário, aos quais se submete. Estará excluido, na hipótese, o contrato de transporte? Os individuos que, à porta de um teatro, adquirem ingressos, não discutem o preço, a hora, a qualidade do espetáculo, prèviamente fixados pela emprêsa. Deixou, por isso, de haver contrato" (31)?

8. Após esta análise das principais controvérsias acêrca da possibilidade do contrato de Direito Público, entre uma pessoa administrativa e um particular, a conclusão a tirar está evidente: os contratos de Direito Público e (o que mais especialmente nos interessa) de Direito Administrativo, não só existem como figura jurídica, transcendente ao direito positivo, senão também podem celebrar-se, assim entre duas ou mais pessoas administrativas, como entre a pessoa administrativa e o particular.

Defronta-nos, agora, a dificuldade da determinação dos caracteres do contrato de Direito Administrativo. Por que caracteres se reconhece um contrato administrativo?

E', para logo, compreensível que o simples fato de ser um dos contraentes pessoa administrativa não é suficiente para caracterizar o contrato como contrato de Direito Administrativo. As pessoas administrativas celebram, por igual, contratos de Direito Privado e, até, de Direito Processual; algumas delas estendem a sua atividade contratual ao próprio Direito das Gentes.

Sôbre a matéria, as duas doutrinas mais difundidas nos vêm da França. A primeira procura caracterizar o contrato de Direito Administrativo pelo fim mediato a que tende, - um fim de serviço público. E' a teoria de

(31) Natureza Jurídica da Concessão de Serviço Pứblico, São Paulo, 1933, p. 81. 
Dugurt (32). A segunda, sem desatender ao elemento finalístico, ajunta-lhe, como complemento, o requisito da eleição do Direito Administrativo para reger o contrato, - eleição feita pela administração e aceita pelo particular. E' a teoria de JÈzE (33), que assim atribui ao Direito Administrativo, nêsse respeito, a feição de direito convencional, fundado sôbre o princípio da autonomia da vontade.

Nenhuma das duas doutrinas é satisfatória. A de Dugurt identifica a execução do serviço público com um dos atos, em que ela se decompõe, afim de caracterizar êsse ato ou, seja, o contrato celebrado pela administração, não pelo seu fim imediato, - mas pelo fim a que se dirige a atividade, em que êle se insere. Êsse critério sòmente seria verdadeiro, se tôda a atividade de execução dos serviços públicos fosse regida pelo Direito Administrativo. Nessa hipótese, realmente, desde que inserível naquela atividade, porque tendente a seu fim específico, o contrato, celebrado pela administração, tornar-se-ia, só por isso, um contrato de Direito Administrativo. Mas bem sabemos que não é assim: atos de Direito Privado podem ser praticados pelas pessoas administrativas na execução do serviço público.

Não escapou à penetração crítica de Gaston JÈze o alcance da objeção. Demonstra-o a conjugação, que se verifica em sua doutrina, entre aquele elemento teleológico e o requisito que lhe apõe da eleição do Direito Administrativo para reger o contrato, feita pelos contratantes. Levađa, porém, às suas últimas consequências, tal doutrina importaria a negação da existência de contratos de Direito Administrativo. Se a aplicação do Direito Administrativo a um contrato dependesse da eleição das partes, não seria,

(32) Ob. cit.. t. II, Paris, 1928, § 27.a p. 380.

(33) Les Principes Généraux du Droit Admnistratif, t. III, Paris, 1926, p. 307. 
evidentemente, o Direito Administrativo que imprimiria feição característica a êsse contrato. Segundo essa concepção, poderiam existir contratos regidos pelo Direito Administrativo; não poderiam existir, entretanto, contratos de Direito Administrativo.

9. Paira numa esfera mais alta a solução da dificuldade, entrelaçando-se com as próprias noções primeiras do Direito Administrativo.

o Direito Administrativo não é um direito fechado (34). Vemos, não raro, reguladas por outros ramos do direito, relações jurídicas, prara as quais no Direito Administrativo se encontrariam moldes legais adequados. Assim, o Direito Administrativo regula a desapropriação. Mas se, para a consecução do bem que se lhe mostra necessário, o Estado recorre, porque é possível, a um contrato de compra e venda, as relações jurídicas que, dêsse modo, se estabelecem, são reguladas pelo Direito Privado. Na hipótese de desapropriação, entretanto, como a situação se desenha? O Estado é forçado, é compelido, não obstante quaisquer resistências dos particulares, a obter os bens, necessários como meios à execução da tarefa estatal: a utilidade púlica o exige. Ao Direito Administrativo cabe, então, regular, "sub specie publicae utilitatis", as relações jurídicas daí resultantes. Diversamente, se pode o Estado adquirir ao particular o bem, de que precisa, usando, para tal fim, a figura jurídica da compra e venda, às relações jurídicas consequentes não se poderia aplicar uma regulamentação, inspirada em considerações de utilidade pública, sem correspondência com a situação real. Aplicar-se-lhes-á, portanto, o Direito Privado.

'(34) FleINER, Institutionen des Deutschen Verwaltungsrechts, Tübingen, 1928, § 2; O. MAYER, Theorie des Französischen Verwaltungsrecht. Strassburg, 1886, $§ 3$, n. 2, p. 18. 
A aplicabilidade do Direito Administrativo supõe, relativamente ao Estado, um "deve", e não um "pode". E' o natural consectário da própria noção de administração pública, entre cujos característicos se conta o de encontrar-se vinculada, legalmente, obrigatòriamente, à realização do fim superior que lhe é proposto: a utilidade pública (35) .

10. Esse "deve", a que aludimos, como caracterizá-lo, porém, nos contratos de Direito Administrativo?

A resposta é simples. Aparecerá êle, segundo entendemos, quando, ao menos, um dos sujeitos e, ao menos, uma das prestações obrigacionais do contrato se encontrarem, legalmente, obrigatòriamente vinculados à finalidade característica da administração pública; isto é, quando, além se encontrar o sujeito, pela sua condição, vinculado mediatamente àquela finalidade, o objeto da ação se encontrar, de modo imediato, vinculadio à mesma finalidade, fixando-se, destarte, em forma de "dever", o que, em relação ao sujeito se formulava em termos de "poder".

Para chegarmos, pois, a afirmar a existência de um contrato de Direito Administrativo, fôrça é que deparemos, no negócio jurídico contratual sob exame, as qualificações seguintes: a) no que concerne aos sujeitos, um, ao menos, há-de ser uma pessoa administrativa, como tal existencialmente vinculada ao fim característico da administração pública e, consequentemente, submetida ao Direito Administrativo; $b$ ) no que respeita ao objeto, - não o objeto da obrigação, mas o objeto de uma, ao menos, das prestações obrigacionais, - êste terá que ser: I) ou alguma cousa do domínio público, ou do patrimônio administrativo, como tal vinculada ao fim característico da administração pú-

(35) Nossa Introdução ao estudo do Direito Administrativo Brasileiro, Pôrto Alegre, 1942, § 2, p. 18 e seguintes; $\S 3$, p 34 e seguintes. 
blica e, por igual submetida ao Direito Público; II) ou um fato que, diretamente, represente o exercício da própria administração pública ou atividade administrativa, como tal regido necessàriamente pelo Direito Administrativo.

11. Foi, quanto nos consta, JeAn Rouvière quem, nesta matéria, pela primeira vez, assinalou, e incidentemente, o paralelismo entre a classificação dos contratos de Direito Administrativo e a classificação dos atos de comércio (36). A analogia entre as duas classificações é, na verdade, a via a eleger para a solução do problema.

Tal como se procede no Direito Mercantil, impõe-se na nossa disciplina, para a caracterização do contrato de Direito Administrativo, o exame analítico dos elementos formadores da estrutura e do conteudo do negócio jurídico, de sorte a apurar-se a pertinência, ou não, ao Direito Administrativo dos que lhe são substanciais em relação ao fim, a que se ordena, a saber: a pessoa, sujeito da obrigação, e a cousa, ou o fato, objeto da prestação.

Quando o sujeito da obrigação e a cousa, ou o fato, objeto da prestação obrigacional (37), se acham submetidos ao Direito Mercantil, apresenta-se-nos o ato de comércio por natureza (38). Semelhantemente, e pela forma que deixamos já exposta, o contrato administrativo por natureza. À sua vez, o direito positivo depara-nos, a par dos contratos administrativos por natureza, contratos administrativos por disposição de lei, "ad instar" dos atos de comércio artificiais. Tal é, em nosso direito positivo, o contrato de subenfiteuse de terrenos de marinha, assim definido pelo artigo 694 do Código Civil. Não é impossivel,

(36) Les Contrats Administratifs, Paris, 1930, p. 45.

(37) Waldemar Frrreira, ob. cit. t. I, n.o 50, p. 278: “.. os bens de raiz têm sido excluidos da esfera mercantil".

(38) Waldemar Ferreira, ob. cit., t. I, n.o 52, p. 288. 
enfim, a existência de contratos administrativos por dependência ou conexão, - questão aberta para a doutrina, que só a legislação poderá resolver. Transcedente, porém, ao direito positivo é, apenas, o contrato administrativo por natureza: os demais são criações da lei.

12. Dentre os contratos correntemente havidos como de Direito Administrativo, destacam-se, pela frequência com que aparecem na vida do Estado e das demais pessoas administrativas, a concessão de serviço público e o contrato de obra pública. Nessas duas hipóteses, a classificação corrente é também a classificação exata. A concessão de serviço público e o contrato de obra pública são, realmente, contratos administrativos por natureza.

$\mathrm{Na}$ concessão de serviço públicc, um dos sujeitos é, sempre, o Estado, ou outra pessoa administrativa. Chama-se-lhe concedente. Pela concessão de serviço público, - concedente delega à outra parte, o concessionário, a execução de um serviço público. E' a outorga da concessão. Aceitando-a, o concessionário assume a obrigação de executar o serviço concedido. Objeto, portanto, d'a prestação obrigacional, incumbente ao concessionário, é a execução do serviço público concedido, quer dizer, um fato que representa o exercício da própria atividade administrativa. Na expressão de Velasco: "pode afirmar-se que o objeto do contrato é administrativo, quando a prestação afeta urn serviço público" (38). Fora de dúvida, temos, pois, na concessão de serviço público, um contrato administrativo por natureza.

Certo, não é da essência da concessão a estrutura do contrato. Pode haver concessão, e não haver contrało. Em regra, porém, tratando-se da execução de serviços públicos, nos quais se faz necessária a aplicação de capitais,

(38) Los Contractos Administrativos, Madrid, 1927, p. 79. 
além do esforço do concessionário, a concessão cosfuma vasar-se na forma do contrato (39).

13. No contrato de obra pública, igualmente, um dos sujeitos é, sempre, o Estado, ou outra pessoa administrativa. Mas que dizer do objeto das respectivas prestações obrigacionais? De um lado, a execução de uma obra; de outro, o preço convencionado. Onde, o elemento especìficamente administrativo?

Devemos, desde logo, atender à peculiar estrutura do contrato de obra pública, evidente em sua formação histórica. À voz latina "locare" não se atribuia primitivamente significado técnico; indicava ela a ação material de pôr alguma cousa à disposição de alguem (40). Sôbre êste fundamento de fato, assenta a figura da "locatio conductio", tanto sob a forma da "locatio rerum", como sob a forma d'a "locatio operis".

Uma e outra supõem que o "locator" coloque uma cousa ("rem locare") à disposição do "conductor"; daquela, êste passa a dispor ("cum ducere"), para usá-la e gozá-la, ou para afeiçoá-la segundo a arte (41).

(39) Nossos Principios cit., § 19, p. 177.

(40) Fubini, Il Contratto di Locazione di Cose, Milano, 1910, t. I, no 1 , nota 1, p. 4.

(41) G. MAY, Eléments de Droit Romain, Paris, 1935, no 156, p. 358: "C'est, semble-t-il, le louage de choses qui servit de type au louage d'industrie. Or dans le louage de choses, le "locator" s'oblige à remettre au "conductor" une chose que celui prend ("cum ducere") à l'effet d'en user et d'en jouir. Cette remise de la chose fut considérée comme le trait caracteristique du louage. On en conclut qu'il n'y aurait louage d'industrie que si les services promis consistaicnt dans un travail là effectuer sur une chose matérielle livrée par. le mattre de cette chose là icelui qui idoit accomplir le travail"; CosTA; Storia del Dtrito Romano Privato, Torino, 1925, p. 398 e 399; AccsRIAS, Précis de Droit Romain, t. Il. Paris, 1891, n.0 620a, p. 332; etc. 
Tal é a estrutura, com que o Direito Romano concebeu o contrato de locação. Daí que na "locatio operis", "locator" se chame ao dono da obra, e ao executor da obra se chame "conductor" (42) ou, por influência do Direito Público, estendendo-se a denominação do contrato de obra pública ao de obra privadia, "redemptor" (43).

A denominação "redemptor", — diga-se de passagem, - sinala a diferenciação entré o contrato de obra pública e o de obra privada. Chama-se ao executor da obra pública "redemptor operis", pela mesma razão, talvez (44), por que LABEÃo chamava "redemptor pontis" ao contratador do pedágio de uma ponte (45), e Papiniano, "redemptor vectigalium", ao contratador de impostos (46). Como o cantratadior de impostos se substitui ao Estado na arrecadação dos tributos, o "redemptor operis" substitui-se ao Estado na execução da obra, de que se incumbe, tomando cada qual sôbre si uma tarefa estatal: resgatam-na; retoma o indivíduo o que se transferira ao Estado.

Conceituado dêsse modo o contrato de obra pública, objeto da prestação do dono da obra é uma cousa ou, quando menos, a delegação de uma tarefa que lhe compete, mas que abandona, pelo contrato, ao executor da obra (47). Em se tratando de obra pública, pertinente ao domínio

(42) A. Peres, Praelectiones in Duodecim Libros Codicis Justiniani, ad lib. IV, tit. LVX, no 1, Opera Varia, Venetiis, 1738, t. I, p. 229.

(43) Mommsen, Romisches Staatsrecht, t. II, Leipzig, 1887, nota 2, p. 448.

(44) Contra, Mommsen, lug. lcit.

(45) Dig., lib. XIX, tit. II, locati conducti, fs. $60, \S 8$.

(46) Dig., lib. L, tit. V, de vacatione et excusatione munerum, fr. $8, \& 1$.

(47) Maynz, Cours de Droit Romain, Bruxelles, 1891, t. 218, p. 248: "les Romains... donnent au maître la qualification de "locator", parce qu'il met l' ouvrage à la disposition de l'autre contractant et lui abandonne l'entreprise..." 
público ou ao patrimônio administrativo, assim a disposição da cousa como a da tarefa cabem privativamente à administração pública e se acham vinculadas aos fins desta, 'já que aos particulares é vedado modificar a destinação ou intervir na gestão do domínio público ou do patrimonio administrativo. Consequentemente, objeto da prestação do executor da obra é, no contrato de obra pública, pertinente ao domínio público ou ao patrimônio administrativo, um fato que representa o exercício por delegação de uma atividade administrativa, especificamente tal.

Assim concebido, inclui-se indubitàvelmente o contrato de obra pública entre os contratos administrativos por natureza. Há, entretanto, contratos de obra pública, que são de Direito Administrativo por disposição de lei. A execução de obra pública, relativa ao patrimônio fiscal, de acôrdo com o que expusemos, não poderia dar origem a um con. trato de Direito Administrativo por natureza. Segundo a tradição de nosso direito positivo, sem embargo, todos os contratos de obra pública, são havidos como de Direito Administrativo (48). Logo, os contratos de obra pública concernentes ao patrimônio fiscal, deverão reputar-se contratos administrativos por disposição da lei.

14. Guiados pelo débil fio da analogia, que apontamos, entre o Direito Mercantil e o Direito Administrativo, logramos chegar, destarte, ao termo de nosso estudo. Ponhamos-lhe como conclusão uma palavra de Stammler, quase "um truismo, tão verdadeira quanto esquecida: Nada

(48) Lei de 29 de agosto de 1828 , notadamente o artigo 6 . 
se pode entender isoladamente. E' sempre necessário comparar (49)!

Tal seja sempre, almejamos, quanto às relações entre o Direito Administrativo e o Direito Mercantil, a inspiração dos sabedores!

(49) Ob. cit., p. 779: “Aus sich selbst kann man nichts verstehen. Es ist immer nötig, die Gegenstände der Betrachtung mit anderem $\mathrm{zu}$ vergleichen und alsdann zuzusehen, wie sie einheitlich erfasst und festgehalten werden können." 